\title{
Metolazone and Furosemide Combination in Cardiorenal Syndrome: Short-Term Safety and Efficacy Among Admitted Patients in a Tertiary Hospital
}

\author{
Bataclan RP ${ }^{1 *}$ and Alonso $\mathrm{RS}^{2}$ \\ ${ }^{1}$ Department of Medicine, University of the East Ramon Magsaysay Medical Center, Philippines \\ ${ }^{2}$ Section of Nephrology, Dept. of Medicine, UP-Philippine General Hospital, Philippines
}

Submission: December 28, 2018; Published: January 22, 2019

*Corresponding author: Rommel P Bataclan, Department of Medicine, University of the East Ramon Magsaysay Medical Center, Aurora Blvd, Brgy, Dona Imelda, Quezon City, Philippines.

\section{Abstract}

Background: Diuretics are considered one of the essential drugs in the management, wherein Furosemide is usually given. But in some cases, it can be ineffective due to diuretic resistance. Metolazone is a thiazide-like diuretic, can be combined with loop diuretics to control volume overload. Since the drug is just newly introduced in our country, this study examines the immediate effect of Metolazone-Furosemide combination and possible adverse reactions in patients with Cardiorenal Syndrome.

Methods: This is an observational study of adult patients admitted at the UP-Philippine General Hospital diagnosed with Cardiorenal Syndrome. All the subjects involved were initially given Furosemide IV either bolus or drip (maximum 200mg/d) and Metolazone $5 \mathrm{mg}$ single dose. The primary outcome measure is the comparison of net hourly output rate, while secondary outcome measures include comparison of serum sodium, potassium, creatinine (baseline and 24 hours after administration), need for dialysis and adverse events.

Results: Forty-six patients were included in the study, most of which have Type 2 Cardiorenal Syndrome (47.8\%, n=22). Overall, there was improvement of the net output hourly rate, without significant change in serum sodium, potassium and creatinine. However, 9 patients (19.6\%) had episodes of hypotension, 6 patients (13\%) still eventually needed hemodialysis and 6 patients had hypokalemia. Three patients (6.5\%) died during hospital stay while the rest were discharged improved.

Conclusion: A combination of Metolazone and Furosemide is a feasible, safe management of patients with Cardiorenal Syndrome.

Keywords: Acute Renal Failure; Pharmacology; Electrolyte Disorders

\section{Introduction}

Table 1: Classification of Cardiorenal Syndrome proposed by Ronco \& Colleagues.

\begin{tabular}{|c|c|c|c|}
\hline Type & Name & Mechanism & Clinical Conditions \\
\hline I & Acute Cardiorenal Syndrome & $\begin{array}{c}\text { Abrupt worsening of kidney function } \\
\text { leading to Acute Kidney Injury (AKI) }\end{array}$ & $\begin{array}{c}\text { Acute cardiogenic shock and } \\
\text { acutely decompensated heart } \\
\text { failure }\end{array}$ \\
\hline II & Chronic Cardiorenal Syndrome & $\begin{array}{c}\text { Chronic abnormalities in cardiac func- } \\
\text { tion causing progressive \& potentially } \\
\text { permanent kidney disease }\end{array}$ & Chronic congestive heart failure \\
\hline III & Acute Renocardiac Syndrome & $\begin{array}{c}\text { Abrupt worsening of kidney function } \\
\text { causing acute cardiac disorder }\end{array}$ & $\begin{array}{c}\text { Acute kidney ischemia \& glomer- } \\
\text { ulonephritis }\end{array}$ \\
\hline IV & Chronic Renocardiac Syndrome & $\begin{array}{c}\text { Chronic kidney disease causing cardi- } \\
\text { ac dysfunction }\end{array}$ & $\begin{array}{c}\text { Chronic kidney disease leading to } \\
\text { heart failure }\end{array}$ \\
\hline V & Secondary Cardiorenal Syndrome & $\begin{array}{c}\text { Systemic condition causing both cardi- } \\
\text { ac and renal dysfunction }\end{array}$ & Diabetes; Sepsis \\
\hline
\end{tabular}


At present, there is already progress in understanding the complex interplay between the cardiovascular and renal system. Although there are still gaps to be answered, it is acknowledged that presence of kidney disease is a risk factor for development of cardiovascular diseases [1,2]. It is also known that cardiovascular disease is the leading cause of death in patients with End Stage Renal Disease [3]. Vice-versa, in the presence of cardiovascular disease, whether acute or long-standing, can also predispose individuals to kidney disease as a short or longterm complication [4]. Due to the bidirectional nature of heartkidney interaction and the vast interrelated derangements that can happen, the term "Cardiorenal Syndrome" was coined. The National Heart, Lung and Blood Institute (NHLBI) defined it as a condition in which therapy to relieve congestive symptoms of heart failure is limited by further decline in renal function [5]. In 2008, Acute Dialysis Quality Initiative (ADQI) consensus group proposed a classification of Cardiorenal Syndrome into categories whose labels reflect the most likely primary and secondary pathology and time frame (Table 1) [6].

Depending on the type of Cardiorenal Syndrome and setting, incidence ranges from 5 to $50 \%$ and found to be an independent risk factor of mortality [7,8]. Cardiac (heart failure) and/or renal dysfunction (manifested by oliguria and azotemia) is the endpoint of this syndrome. This usually leads to fluid retention and subsequently volume overload, which is one of the main reasons for further worsening of both systems, and potentially fatal $[3,9]$. If present, managing volume overload is one of the immediate goals in order to relieve symptoms and prevent further complications $[10,11]$. Diuresis has become an integral part in the management of volume overload associated with Cardiorenal Syndrome. Of particular use is intravenous loop diuretics, which is easily available and has long history of clinical experience. Theoretically, increasing urine output will help relieve congestion, facilitating prompt relief of symptoms [11]. Also, diuretics is said to flush out debris to limit acute tubular obstruction and decrease tubular cell metabolic demand, consequently preventing Acute Tubular Necrosis (ATN). However, clinical studies have proven otherwise. There has been note of increased mortality in observational studies, presumably due to electrolyte imbalance, leading to dysrhythmias and sudden cardiac death [12]. In addition, analysis of the data from the Evaluation Study of Congestive Heart Failure and Pulmonary Artery Catheterization Effectiveness (ESCAPE) study demonstrated a nearly linear relationship between loop diuretic dose and mortality over 6 months of follow-up in patients hospitalized with advanced heart failure [13].

There are several mechanisms that can possibly explain the limited efficacy of loop diuretics alone. Heart failure, which is a feature in cases of Cardiorenal Syndrome, shifts the dose response curve of diuretics, downward and right, hence the need of higher dose. Also, progressively diminishing response to diuretics called "braking phenomenon" is frequent. This is related to activation of the Renin-Angiotensin-Aldosterone Axis and Sympathetic Nervous System, reducing renal blood flow and increasing sodium reabsorption in the proximal tubule [14]. Distal tubule hypertrophy, tubular hyperfunction and concomitant reduced glomerular filtration rate are additional pathophysiological changes among these patients, and these may lead to Diuretic Resistance. Patients with heart failure with diuretic resistance also have poor outcomes, which may be a function of their more severe underlying disease process [15].

Besides optimization of loop diuretic dosing (i.e. increase frequency; continuous drip) and investigating other causes (i.e. Excessive Sodium Intake, Nephrotoxic Drugs), sequential nephron blockade is another option to overcome diuretic resistance. In majority of situations, a thiazide-type diuretic is given in addition to loop diuretic. Its additive effect is related to increased delivery of $\mathrm{Na}+$ to the more distal thiazide-sensitive segments of the kidney and changes in distal tubular cell structure and/or function [16].

One of the thiazide-type diuretics used is Metolazone, which structurally differs from this drug class with the methyl group in C-2 and o-tolyl group in C-3. It is the only drug in its class which acts on both the cortical thick ascending limb at the Loop of Henle (proximal tubule) and the distal convoluted tubule. This makes sodium excretion more effective and further inhibits sodium reabsorption [17]. It is also said that Metolazone causes electrolyte abnormalities less frequently, hence it does not commonly cause hyperlipidemia and hyperglycemia found in other thiazide diuretics [18]. In studies, Metolazone was found to increase urine output in various fluid overload states such as Ascites/Liver Cirrhosis [19,20], Nephrotic Syndrome [19,21] and Chronic Kidney Disease [22]. There are numerous studies also in patients with Congestive Heart Failure, with varying results $[14,19,21,23]$.

The drug was just introduced in our country about eight years ago. There were no previous local studies with regards to the drug and since the above-mentioned studies are mostly from the last century, no known studies on Heart Failure using the Cardiorenal Syndrome classification. Hence, the aim of the study was to describe the initial experience of combination therapy of Furosemide and Metolazone in patients with Cardiorenal Syndrome, in terms of efficacy, safety and outcome.

\section{Methodology}

\section{Study Site and Population}

This is a retrospective observational study in a single tertiary university hospital. All adult patients ( $>18$ years old) admitted at the UP-Philippine General Hospital from October 2011 to September 2012, diagnosed with Cardiorenal Syndrome, as defined by the Acute Dialysis Quality Initiative Consensus Group. Patients were included regardless of etiology, severity \& type of cardiac dysfunction. Patients were excluded if:

a) They are diagnosed case of End Stage Renal Disease, with history of renal replacement therapy (dialysis, kidney transplant) 
b) Patient or relatives opted not to have aggressive management or medical treatment (i.e. Advanced Directives; Do Not Resuscitate)

c) Serum creatinine, other labs were not available prior to giving of the intervention.

\section{Intervention, Data Collection and Statistics}

Baseline demographics, cardiac diagnosis, co-morbidities, other medical problems and initial medications/ interventions were collected. Initial (on admission or prior to administration of Metolazone) serum creatinine, sodium, potassium and urine output were also noted. All of the subjects involved were initially given Furosemide IV either bolus or drip (maximum $200 \mathrm{mg} / \mathrm{d}$ ). Metolazone $5 \mathrm{mg}$ single dose was subsequently added in all subjects, duration varies based on clinical assessment. Urine output was noted for the first 24 hours after Metolazone was given, as well as repeat serum creatinine, sodium and potassium. Clinical course was also noted up to the final disposition of all subjects.
The primary outcome measure is the comparison of hourly output rate (before versus after giving of Metolazone), while secondary outcome measures include comparison of serum sodium, potassium, creatinine, symptomatic relief within 24 hours, need for dialysis and adverse events such as hypotension, hypokalemia and death. Descriptive statistics were made, with computation of frequency percentage or mean + standard deviation if applicable. For comparison of the laboratories, analysis of variance (ANOVA) computed at 95\% Confidence Interval, with p-value of less than 0.05 deemed to be statistically significant. Data were analyzed using the STATA 9.1 software (STATA corp., Texas, USA).

\section{Results}

Forty-six patients were included in the study, most of which have Type 2 Cardiorenal Syndrome $(47.8 \%, n=22)$. Table 2 shows the clinical characteristics of included subjects. Majority of subjects were males, with Hypertension, Diabetes. More frequently, subjects had Acute Kidney Injury with severity index of RIFLE-I.

Table 2: Baseline characteristics of patients in the study

\begin{tabular}{|c|c|}
\hline & Frequency (\%) \\
\hline Mean Age $( \pm$ SD) & $67.06 \pm 19.83$ years \\
\hline \multicolumn{2}{|c|}{ Gender } \\
\hline Male & $29(63.0 \%)$ \\
\hline Female & $17(37.0)$ \\
\hline \multicolumn{2}{|c|}{ Co-Morbidities } \\
\hline Coronary Artery Disease & $19(41.3 \%)$ \\
\hline Chronic Kidney Disease & $9(19.5)$ \\
\hline COPD & $4(8.7)$ \\
\hline Cerebrovascular Disease & $7(15.2)$ \\
\hline Diabetes Mellitus & 27 (58.7) \\
\hline Dyslipidemia & $19(41.3)$ \\
\hline Hypertension & $38(82.6)$ \\
\hline Asthma & $2(4.3)$ \\
\hline \multicolumn{2}{|c|}{ AKI-Severity } \\
\hline RIFLE-R & $14(30.4 \%)$ \\
\hline RIFLE-I & $22(47.8)$ \\
\hline RIFLE-F & $10(21.8)$ \\
\hline \multicolumn{2}{|c|}{ Cardiorenal Syndrome Type } \\
\hline 1 & $9(19.6 \%)$ \\
\hline 2 & $22(47.8)$ \\
\hline 3 & $3(6.5)$ \\
\hline 4 & $1(2.2)$ \\
\hline 5 & $11(23.9)$ \\
\hline Oliguria/ Anuria & $14(30.4 \%)$ \\
\hline Mechanical Ventilator & $9(19.6 \%)$ \\
\hline Inotropic Support & $11(23.9 \%)$ \\
\hline \multicolumn{2}{|c|}{ Organ System Failure } \\
\hline Respiratory & $9(19.6 \%)$ \\
\hline
\end{tabular}




\begin{tabular}{|c|c|}
\hline Liver & $2(4.3)$ \\
\hline Hematologic & $4(8.7)$ \\
\hline Neurologic & $7(15.2)$ \\
\hline
\end{tabular}

Almost all of the patients were started with continuous Furosemide drip (dose range $10-20 \mathrm{mg} / \mathrm{hr}$ ), while the rest were given intermittent intravenous Furosemide (dose range 4080mg every 4-6 hours). Half of the patients were administered with Metolazone within 2 hours after Furosemide was started, a third of them meanwhile were given Metolazone prior to start of Furosemide, and rest started 2-6 hours after. Concomitant medications given to these patients is described in (Table 3).

Table 3: Diuretic administration and concomitant medications given.

\begin{tabular}{|c|c|c|c|}
\hline & Frequency (\%) & & Frequency (\%) \\
\hline Furosemide dose (mg/d) & & Oral/ Other routes & \\
\hline Continuous drip & & Anti-platelets & $31(67.4 \%)$ \\
\hline \multirow[t]{2}{*}{ Intermittent } & $41(89.1 \%)$ & Anti-diabetes & $9(19.6)$ \\
\hline & $5(10.9)$ & Anti-dysrhythmia & $4(8.6)$ \\
\hline Timing Metolazone & & Anti-hypertensive & \\
\hline Before Furo & $15(32.6 \%)$ & ACE/ARB & $37(80.4 \%)$ \\
\hline Within 2 hrs after & $23(50.0)$ & $\mathrm{a} / \mathrm{b}$ Blocker & $18(39.1)$ \\
\hline 2-6 hrs after & $8(17.4)$ & Beta-blocker & $9(19.5)$ \\
\hline Parenteral Medications & & ССВ & $18(39.1)$ \\
\hline Antibiotics & $27(58.7 \%)$ & Nitrates & $23(50.0)$ \\
\hline Inotropes & & Bronchodilators & $13(28.2)$ \\
\hline Dobutamine & $3(6.5)$ & Calcium supp. & $9(19.6)$ \\
\hline Dopamine & $17(37.0)$ & Digitalis & $14(30.4)$ \\
\hline Norepinephrine & $6(13.0)$ & Iron/Vitamins & $25(54.3)$ \\
\hline Arrhythmia drugs & $4(8.6)$ & Statins & $42(91.3)$ \\
\hline Insulin & $18(39.1)$ & & \\
\hline
\end{tabular}

Table 4: Clinical parameters in patients when initially given Furosemide as compared to Furosemide-Metolazone combination.

\begin{tabular}{|c|c|c|c|}
\hline & Furosemide only & After Metolazone-Furo & p-value \\
\hline Hourly output & $11.24 \pm 451 \mathrm{cc} / \mathrm{hr}$ & $33.20 \pm 771 \mathrm{cc} / \mathrm{hr}$ & $<0.01$ \\
\hline Serum Sodium & $137.3 \pm 11.7 \mathrm{mmol} / \mathrm{l}$ & $136.5 \pm 4.68 \mathrm{mmol} / \mathrm{l}$ & 0.28 \\
\hline Serum Potassium & $4.14 \pm 0.54 \mathrm{mmol} / \mathrm{l}$ & $3.89 \pm 0.27 \mathrm{mmol} / \mathrm{l}$ & 0.13 \\
\hline Serum Creatinine & $3.33 \pm 8.74 \mathrm{mg} / \mathrm{dl}$ & $2.85 \pm 7.42$ & 0.49 \\
\hline
\end{tabular}

Overall, there was an improvement of the net output hourly rate, without significant change in serum sodium, potassium and creatinine Table $4.78 .2 \%$ of the patients (36 of 46 patients) experienced symptomatic relief within 24 hours, based on the review of charts. However, nine (9) patients (19.6\%) had episodes of hypotension, six (6) patients (13\%) still eventually needed hemodialysis and same number of patients had hypokalemia. Although majority of patients were diabetics, no significant hyperglycemia occurred on all patients. Three patients $(6.5 \%)$ died during hospital stay while the rest were discharged improved [24].

\section{Discussion}

This study showed improvement of diuresis among patients with Cardiorenal Syndrome when given a diuretic combination of Furosemide and Metolazone. It resulted in symptomatic improvement in almost four-fifths of patients, without causing significant electrolyte abnormalities and high 
percentage of mortalities. Significant diuresis and good safety profile with Metolazone-Furosemide were also noted in other studies. The randomized trial done by Channer comparing Metolazone against Bendrofluazide (another Thiazide diuretic) also showed significant diuresis in more than $90 \%$ of patients, without significant changes in serum sodium, potassium urea \& creatinine [25]. In a study by Desai and colleagues, adding Metolazone $5 \mathrm{mg}$ showed an average weight loss of $4.78 \mathrm{~kg}$ in 6 days, with significant increase in urine volume and urine sodium. This was achieved without significant increase of urine potassium excretion, creatinine, blood sugar and lipid profile and creatinine. There was some increase in serum sodium, but majority still has normal values [26]. Meanwhile, in a retrospective cohort study by $\mathrm{Ng}$ and colleagues showed that Furosemide-Metolazone regimen showed significant increase in urine output compared to Continuous Furosemide Infusion. Incidence of worsening renal function was not different between regimens; however, blood urea nitrogen (BUN) tended to increase more and incidence of hyponatremia was higher with Furosemide-Metolazone combination [27]. In an early study of African patients by Gunstone and colleagues showed that Metolazone combined with Furosemide showed success in $47 \%$ of patients with Congestive Heart Failure, defined as weight loss of $0.5 \mathrm{~kg} /$ day for at least 4 days [19].

Weight loss was initially considered as an outcome. However, since this parameter was not monitored routinely in CHF patients in our institution (and inability to monitor in some patients in the ICU due to instrument limitations), we did not include this as a surrogate marker. The medication was still in its initial phase of approval from the Food and Drug Administration (Compassionate Use) at the time the study was collated, hence the retrospective nature, which encompass the usual limitations.

\section{Conclusion}

There are ongoing randomized controlled trials for this diuretic combination and hope to further shed light on its efficacy and long-term safety. In conclusion, Metolazone and Furosemide combination is a feasible, safe management of patients with Cardiorenal Syndrome.

\section{Conflict of Interest}

The authors have no financial interests related to the study and the funding was primarily out-of-pocket.

\section{References}

1. Sarnak MJ, Levey AS, Schoolwerth AC, Coresh J, Culleton B, et al. (2003) Kidney Disease as a Risk Factor for Development of Cardiovascular Disease: : A statement from the American Heart Association Councils on Kidney in Cardiovascular Disease, High Blood Pressure Research, Clinical Cardiology, and Epidemiology and Prevention. Hypertension 108(17): 2154-2169.

2. Weir MR (2011) Recognizing the Link between Chronic Kidney Disease and Cardiovascular Disease. Am J Manag Care.; 17: S396-S402.

3. Mahapatra HS, Lalmalsawma R, Singh NP, Kumar M, Tiwari SC (2009) Cardiorenal Syndrome. Indian J Kidney Dis 3: 61-70.
4. Elsayed EF, Tighiouart H, Griffith J, Kurth T, Levey AS, Salem D, et al. (2007) Cardiovascular Disease and Subsequent Kidney Disease. Arch Intern Med 167(11): 1130-1136.

5. (2004) National Heart, Lung and Blood Institute. Cardio-Renal Connections in Heart Failure and Cardiovascular Disease: NHLBI Scientific Report.

6. Ronco C, McCullough P, Anker SD, Inand I, Aspromonte N, et al. (2010) Cardio-renal syndromes: report from the Consensus Conference of the Acute Dialysis Quality Initiative (ADQI) Group. Eur Heart J 31(6): 703711.

7. Eren Z, Ozveren O, Buyukoner E, Kaspar E, Degertekin M, Kantarci G (2012) A Single-Centre Study of Acute Cardiorenal Syndrome: Incidence, Risk Factors and Consequences. Cardiorenal Med 2(3): 168176.

8. Cruz DN, Bagshaw SM (2011) Heart-Kidney Interaction: Epidemiology of Cardiorenal Syndromes. Int J Nephrol 11: 351291.

9. Ronco C, Maisel A (2010) Volume Overload and Cardiorenal Syndromes. Congest Heart Fail 16 (Supp. 1): S1-S4.

10. Tang WHW, Mullens W (2010) Cardiorenal syndrome in decompensated heart failure. Heart 96: 255-260.

11. House AA, Haapio M, Lassus J, Bellomo R, Ronco C (2010) Therapeutic Strategies for Heart Failure in Cardiorenal Syndromes. Am J Kidney Dis 56 (4): 759-773.

12. Felker GM, O'Connor CM, Braunwald E (2009) Loop Diuretics in Acute Decompensated Heart Failure Necessary? Evil? A Necessary Evil? Circ Heart Fail 2(1): 56-62.

13. Hasselblad V, Stough WG, Shah MR, Lokhnygina Y, O'Connor CM, et al. (2007) Relation between dose of loop diuretics and outcomes in a heart failure population: results of the ESCAPE Trial. Eur J Heart Fail 9(10): 1064-1069.

14. Jentzer JC, DeWald TA, Hernandez AF (2010) Combination of Loop Diuretics with Thiazide-Type Diuretics in Heart Failure. J Am Coll Cardiol 56(19): 1527-1534.

15. Neuberg GW, Miller AB, O'Connor CM, Belkin RN, Carson PE, et al (2002) Diuretic resistance predicts mortality in patients with advanced heart failure. Am Heart J 144(1): 31- 38.

16. Sica DA (2011) Diuretic use in renal disease. Nat Rev Nephrol 8(2): 100-109.

17. Smiley JW, Onesti G, Swartz C (1972) The acute effects of Metolazone on electrolyte and acid excretion in man. Clin Pharmacol Ther 13(3): 336-342.

18. Sica DA (2006) Diuretic-related side effects: development and treatment. J Clin Hypertens 6(9): 532-540.

19. Gunstone RF, Wing AJ, Shani HGP, Njemo D, Sabuka EMW (1971) Clinical experience with Metolazone in fifty-two African patients: Syngergy with Frusemide. Postgrad Med J 47(554): 789-793.

20. Lang GR, Westenfelder C, Nascimento L, Dhupelia VB, Arruda JA, et al. (1977) Metolazone and Spironolactone in Cirrhosis and the Nephrotic Syndrome. Clin Pharmacol Ther 21(2): 234-243.

21. Garin EH (1987) A comparison of combinations of diuretics in nephrotic edema. Am J Dis Child 141(7): 769-771.

22. Hase NK, Rajadhyaksha G, Guthe S (2006) Diuretic Efficacy and Tolerability of Metolazone in Chronic Kidney Disease: A Clinical Trial Report. Indian Practitioner 59(7): 429-434.

23. Ghose RR, Gupta SK (1981) Syngergistic action of metolazone with "loop" diuretics. BMJ 282(6274): 282:1873.

24. Allen JM, Hind CRK, McMichael HB (1981) Metolazone with loop diuretics in heart failure. BMJ 282: 1873. 
25. Channer KS, McLean KA, Matthew PL, Richardson M (1994) Combination diuretic treatment in severe heart failure: a randomized controlled trial. Br Heart J 71(2): 146-150.

26. Desai N, Singh RK, Adiaga S (2007) Diuretic Efficacy and Tolerability of Metolazone in Chronic Congestive Cardiac Failure - A Clinical Trial Report. Indian Med Gazette 8: 452-455.
27. Ng TMH, Konopka E, Hyderi AF, Hshieh S, Tsuji Y, et al. (2013) Metolazone-Based Diuretic Regimens to Furosemide in Acute Heart Failure. J Cardiovasc Pharmacol Ther 18(4): 343-351.
This work is licensed under Creative

$\begin{array}{ll}\text { (CC) Commons Attribution 4.0 License } \\ \text { BY } & \text { DOI: 10.19080/JOJUN.2019.06.555686 }\end{array}$
Your next submission with Juniper Publishers will reach you the below assets

- Quality Editorial service

- Swift Peer Review

- Reprints availability

- E-prints Service

- Manuscript Podcast for convenient understanding

- Global attainment for your research

- Manuscript accessibility in different formats

( Pdf, E-pub, Full Text, Audio)

- Unceasing customer service

Track the below URL for one-step submission https://juniperpublishers.com/online-submission.php 